\title{
DOSES E FONTES DE NITROGÊNIO EM PASTAGEM DE CAPIM-MARANDU. I - ALTERAÇÕES NAS CARACTERÍSTICAS QUÍMICAS DO SOLO ${ }^{(1)}$
}

\author{
Kátia Aparecida de Pinho Costa ${ }^{(2)}$, Valdemar Faquin ${ }^{(3)}$, Itamar Pereira de \\ Oliveira $^{(4)}$, Cristiane Rodrigues ${ }^{(5)} \&$ Eduardo da Costa Severiano ${ }^{(6)}$
}

\begin{abstract}
RESUMO
A deficiência de $\mathrm{N}$ é uma das principais causas de degradação de pastagens cultivadas, principalmente do gênero Brachiaria. A reconstituição da fertilidade do solo é um dos caminhos para recuperar a capacidade produtiva de pastagem em degradação. Dentre os nutrientes, destaca-se o N, que é o grande responsável pela recuperação dessas áreas. Diante disso, objetivou-se avaliar o efeito da aplicação de doses e fontes de $\mathrm{N}$ em pastagem de capim-marandu em estádio moderado de degradação, por um período de três anos, sobre atributos químicos do solo, como pH, teores de Al trocável, matéria orgânica do solo, $\mathrm{N}$ total e $\mathrm{N}$ inorgânico $\left(\mathrm{N}_{-} \mathrm{NO}_{3}^{-}, \mathrm{N}-\mathrm{NH}_{4}{ }^{+}\right)$. O experimento foi realizado de julho de 2003 a março de 2006, na Fazenda Modelo da UEG, numa área de $882 \mathrm{~m}^{2}$. A pastagem já se encontrava estabelecida há mais de 10 anos, com baixa produção de forragem. 0 delineamento experimental utilizado foi em blocos casualizados com parcelas subdivididas no tempo, com três repetições. Foi utilizado o esquema fatorial $2 \times 4$, sendo duas fontes de $\mathrm{N}$ (sulfato de amônio e uréia) e quatro doses de $\mathrm{N}$ elemento $(0,100,200$ e $\left.300 \mathrm{~kg} \mathrm{ha}^{-1} \mathrm{ano}^{-1}\right)$. Após três anos de aplicação contínua com as maiores doses de $\mathrm{N}$, o pH do solo diminuiu de 5,6 para 4,6 e o teor de $\mathrm{Al}^{3+}$ aumentou de 0,05 para $0,41 \mathrm{cmol}_{\mathrm{c}} \mathrm{dm}^{-3}$; o sulfato de amônio causou maior acidificação do solo em relação à uréia. A aplicação de doses elevadas de $\mathrm{N}$ aumentou os teores de $\mathrm{Al}^{3+}, \mathrm{MO}, \mathrm{N}$ total, $\mathrm{N}-\mathrm{NO}_{3}{ }^{-}$e N-NH${ }_{4}^{+}$no solo, e os teores de $\mathrm{N}_{-} \mathrm{NH}_{4}{ }^{+}$foram mais elevados que os de $\mathrm{N}-\mathrm{NO}_{3}{ }^{-}$
\end{abstract}

Termos de indexação: pH, Al trocável, matéria orgânica do solo, nitrogênio total e nitrogênio inorgânico.

\footnotetext{
(1) Parte da Tese de Doutorado da primeira autora, apresentado a Universidade Federal de Lavras, para obtenção do título de Doutor em Ciência do Solo. Recebido para publicação em agosto de 2007 e aprovado em maio de 2008.

(2) Professora da Universidade de Rio Verde - FESURV. E-mail: katiazoo@hotmail.com

(3) Professor Titular, Departamento de Ciência do Solo da Universidade Federal de Lavras - DCS/UFLA. Caixa Postal 37, CEP 37200-000 Lavras (MG). Bolsista CNPq. E-mail: vafaquin@ufla.br

(4) Pesquisador da Embrapa Arroz e Feijão. Santo Antônio de Goiás (GO). E-mail: itamar.agro@yahoo.com.br

(5) Mestranda em Solo e Água, Escola de Agronomia, Universidade Federal de Goiás. E-mail: crissolocria@yahoo.com.br

(6) Doutorando em Ciência do Solo, Departamento de Ciência do Solo, UFLA. Bolsista CNPq. E-mail: severianoec@yahoo.com.br
} 


\title{
SUMMARY: NITROGEN DOSES AND SOURCES IN MARANDU PASTURE. I - CHANGES IN SOIL CHEMICAL PROPERTIES
}

\begin{abstract}
Nitrogen deficiency is one of the important causes of degradation of cultivated pasture, mainly in the case of Brachiaria pastures. Soil recovery is a way to restore the productive capacity of pastures in degradation. Among nutrients, nitrogen is considered essential and largely responsible for pasture area recovery. The research objective was to evaluate the effects of application of nitrogen doses and sources on marandu grass pasture over a period of three years, based on soil chemical characteristics such as $\mathrm{pH}$, exchangeable aluminum, soil organic matter, total nitrogen and inorganic nitrogen $\left(\mathrm{N}-\mathrm{NO}_{3}^{-}, \mathrm{N}-\mathrm{NH}_{4}^{+}\right)$. The experiment was carried out from July 2003 to March 2006 on a model farm of the Universidade Estadual de Goiás, in an area of $882 \mathrm{~m}^{2}$. Pasture had been grown for more than ten years and was considered in moderate degradation phase, in view of the low herbage yields. A split-plot combination with three replications was used. The experiment had a complete randomized block, $2 \times 4$ factorial design, with two $N$ sources (ammonium sulfate and urea) and four $N$ doses $\left(0,100,200\right.$, and $\left.300 \mathrm{~kg} \mathrm{ha}^{-1} \mathrm{yr}^{-1}\right)$. After three years of continuous nitrogen application at highest doses to marandu grass, the soil $\mathrm{pH}$ decreased from 5.6 to 4.6 and $\mathrm{Al}^{3+}$ content increase from 0.05 to $0.41 \mathrm{cmol}_{c} \mathrm{dm}^{-3}$. The ammonium sulfate source increased soil acidity more than urea. Application of high nitrogen rates increased Al and organic matter contents, soil total nitrogen, $\mathrm{N}-\mathrm{NO}_{3}{ }^{-}$and $\mathrm{N}-\mathrm{NH}_{4}{ }^{+}$. The $\mathrm{N}-\mathrm{NH}_{4}{ }^{+}$contents were higher than $\mathrm{N}_{-} \mathrm{NO}_{3}{ }^{-}$in all nitrogen doses and years evaluated.
\end{abstract}

Index terms: exchangeable aluminum, $\mathrm{pH}$, soil organic matter, total nitrogen, inorganic nitrogen.

\section{INTRODUÇÃO}

A disponibilidade de $\mathrm{N}$ no solo depende do balanço entre os processos de mineralização e os de imobilização. Em pastagens tropicais extensivamente manejadas, sem adubação nitrogenada, a disponibilidade de $\mathrm{N}$ depende, em grande parte, da mineralização do $\mathrm{N}$ dos resíduos vegetais. O balanço entre esses processos pode variar com o tempo e, principalmente, com a natureza do resíduo orgânico em decomposição, além de depender da atividade microbiana do solo (Marschner, 1997; Aita \& Giacomini, 2007).

Os adubos nitrogenados mais comercializados e utilizados em pastagens no Brasil são a uréia (44 a $46 \%$ de N) e o sulfato de amônio (20 a $21 \%$ de N). O uso dessas fontes apresenta vantagens e desvantagens. A uréia tem como vantagens menor custo por quilograma, apresenta alta concentração de N, é de fácil manipulação e causa menor acidificação no solo, o que a torna potencialmente superior a outras fontes do ponto de vista econômico, mas comumente apresenta maior perda de $\mathrm{N}$ por volatilização (Primavesi et al., 2004; Martha Júnior et al., 2004). Por sua vez, o sulfato de amônio apresenta as vantagens de ter menor perda de $\mathrm{N}$ por volatilização $\mathrm{e}$ ser fonte de $\mathrm{S}(24 \% \mathrm{~S})$, embora apresente maior custo por quilograma de N (Primavesi et al., 2004). O fornecimento de $\mathrm{S}$ é extremamente vantajoso para as pastagens estabelecidas na região do Cerrado, cujos solos apresentam baixa disponibilidade desse elemento (Sousa et al., 2001). Tisdale et al. (1993) afirmam que o suprimento adequado de $\mathrm{S}$ no solo aumenta a resposta da planta forrageira ao $\mathrm{N}$ aplicado e pode melhorar a sua eficiência de uso. Contudo, o sulfato de amônio apresenta a desvantagem de promover maior acidificação do solo, em relação àquela gerada pela uréia e pelo nitrato de amônio (Primavesi et al., 2004).

Lange et al. (2006) relataram que a fertilização com uréia, por ser uma molécula de reação básica, inicialmente provoca aumento do $\mathrm{pH}$, principalmente ao redor dos grânulos do adubo. Entretanto, após a nitrificação do amônio, originado da hidrólise da uréia, o $\mathrm{pH}$ decresce para valores inferiores aos originais. A acidificação provocada pelo uso de adubos nitrogenados pode alterar também outros atributos químicos do solo, como aumento do teor de Al trocável, redução da CTC efetiva e das bases trocáveis e, conseqüentemente, aumento da necessidade de calagem (Paiva, 1990).

Estudos indicam que o uso de adubos nitrogenados em pastagens, normalmente, aumenta o teor de $\mathrm{N}$ total, nitrato e amônio no solo. Contudo, aplicações sucessivas com doses altas podem provocar abaixamento do $\mathrm{pH}$ (Campos, 2004; Bonfim-da-Silva, 2005; Batista, 2006; Lange et al., 2006).

Nesse contexto, objetivou-se avaliar o efeito da aplicação de doses e fontes de $\mathrm{N}$ em pastagem de capim-marandu em estádio moderado de degradação, por um período de três anos, sobre atributos químicos do solo, como $\mathrm{pH}$, Al trocável ( $\left.\mathrm{Al}^{3+}\right)$, MO do solo (MOS), $\mathrm{N}$ total e $\mathrm{N}$ inorgânico $\left(\mathrm{N}-\mathrm{NO}_{3}{ }^{-}\right.$e N-NH$\left.{ }_{4}{ }^{+}\right)$. 


\section{MATERIAL E MÉTODOS}

O experimento foi conduzido de julho de 2003 a março de 2006 na Fazenda Modelo do curso de Zootecnia da Universidade Estadual de Goiás, em São Luís de Montes Belos-GO, a 579 m de altitude, $16^{\circ} 31$ ' 30 "de latitude sul e 5022 ' 20 " de longitude oeste. A área de pastagem utilizada foi de $882 \mathrm{~m}^{2}$ dividida em três blocos de $294 \mathrm{~m}^{2}$, com parcelas de $20 \mathrm{~m}^{2}$ e área útil de $6 \mathrm{~m}^{2}$. A pastagem já se encontrava estabelecida há mais de 10 anos, com estádio moderado de degradação, apresentando pouca cobertura do solo, com baixa produção de forragem, devido à exploração intensiva de animais e à falta de reposição de nutrientes no solo.

O delineamento experimental utilizado foi em blocos casualizados com parcelas subdivididas no tempo, com três repetições. Foi utilizado o esquema fatorial $2 \times 4$, sendo duas fontes de $\mathrm{N}$ (sulfato de amônio e uréia) e quatro doses de $\mathrm{N}\left(0,100,200\right.$ e $300 \mathrm{~kg} \mathrm{ha}^{-1}$ ano $\left.^{-1}\right)$.

O solo foi classificado como Latossolo Vermelho distrófico (Embrapa, 2006) de textura argilosa, cujas médias das características químicas de todas as parcelas, na profundidade de $0-20 \mathrm{~cm}$, estão apresentadas no quadro 1. A metodologia utilizada na análise de solo foi a descrita por Silva (1999).

No primeiro ano (2003) foram aplicados $500 \mathrm{~kg} \mathrm{ha}^{-1}$ de calcário dolomítico com 85 \% de PRNT a lanço, 60 dias antes do período chuvoso. Em setembro, após as primeiras chuvas foram aplicados $150 \mathrm{~kg} \mathrm{ha}^{-1} \mathrm{de}_{2} \mathrm{O}_{5}$, $80 \mathrm{~kg} \mathrm{ha}^{-1}$ de $\mathrm{K}_{2} \mathrm{O}$ e $30 \mathrm{~kg} \mathrm{ha}^{-1}$ de FTE BR-12, utilizando como fontes: superfosfato simples, cloreto de $\mathrm{K}$ e fritas, respectivamente. A partir dos resultados da análise química do solo realizada no segundo ano

Quadro 1. Características químicas do solo avaliadas antes da aplicação dos tratamentos em 2003, 2004 e 2005

\begin{tabular}{|c|c|c|c|}
\hline Característica & 2003 & 2004 & 2005 \\
\hline $\mathrm{pH}\left(\mathrm{CaCl}_{2}\right)$ & 5,2 & 5,1 & 4,6 \\
\hline $\mathrm{Al}^{3+}\left(\mathrm{cmol}_{\mathrm{c}} \mathrm{dm}^{-3}\right)$ & 0,0 & 0,1 & 0,2 \\
\hline P-Mehlich - $1\left(\mathrm{mg} \mathrm{dm}^{-3}\right)$ & 1,3 & 6,4 & 1,8 \\
\hline $\mathrm{K}^{+}\left(\mathrm{cmol}_{\mathrm{c}} \mathrm{dm}^{-3}\right)$ & 0,42 & 0,23 & 0,11 \\
\hline $\mathrm{Ca}^{2+}\left(\mathrm{cmol}_{\mathrm{c}} \mathrm{dm}^{-3}\right)$ & 2,70 & 2,79 & 2,20 \\
\hline $\mathrm{Mg}^{2+}\left(\mathrm{cmol}_{\mathrm{c}} \mathrm{dm}^{-3}\right)$ & 1,00 & 0,91 & 0,23 \\
\hline $\mathrm{H}+\mathrm{Al}\left(\mathrm{cmol}_{\mathrm{c}} \mathrm{dm}^{-3}\right)$ & 3,9 & 5,3 & 3,5 \\
\hline $\mathrm{CTC}\left(\mathrm{cmol}_{\mathrm{c}} \mathrm{dm}-3\right)$ & 8,0 & 8,23 & 6,5 \\
\hline $\mathrm{SO}_{4}^{2-}\left(\mathrm{mg} \mathrm{dm}^{-3}\right)$ & 9,8 & 18,9 & 30,0 \\
\hline $\mathrm{Cu}\left(\mathrm{mg} \mathrm{dm}^{-3}\right)$ & 0,4 & 1,7 & 1,0 \\
\hline $\mathrm{Zn}(\mathrm{mg} \mathrm{dm}-3)$ & 0,2 & 2,9 & 0,7 \\
\hline $\mathrm{Fe}\left(\mathrm{mg} \mathrm{dm^{-3 } )}\right.$ & 13,0 & 30,0 & 31,3 \\
\hline $\operatorname{Mn}\left(\mathrm{mg} \mathrm{dm}^{-3}\right)$ & 27,4 & 41,0 & 15,6 \\
\hline $\operatorname{MO}\left(\mathrm{g} \mathrm{dm}^{-3}\right)$ & 11,0 & 18,0 & 20,0 \\
\hline
\end{tabular}

(2004), foi realizada adubação de manutenção com $50 \mathrm{~kg} \mathrm{ha}^{-1}$ de $\mathrm{P}_{2} \mathrm{O}_{5}$ e $100 \mathrm{~kg} \mathrm{ha}^{-1}$ de $\mathrm{K}_{2} \mathrm{O}$, fornecidos mediante a aplicação superfosfato simples e cloreto de K. No terceiro ano de recuperação (2005), foram aplicados $150 \mathrm{~kg} \mathrm{ha}^{-1}$ de $\mathrm{P}_{2} \mathrm{O}_{5}, 120 \mathrm{~kg} \mathrm{ha}^{-1} \mathrm{de} \mathrm{K}_{2} \mathrm{O}$ e $20 \mathrm{~kg} \mathrm{ha}^{-1}$ de FTE BR-12, nas formas de superfosfato simples, cloreto de $\mathrm{K}$ e fritas, respectivamente. A adubação de manutenção foi feita de acordo com Sousa \& Lobato (2004), sendo realizada em uma única aplicação a lanço, no início do período chuvoso (setembro), antes dos fertilizantes nitrogenados.

A adubação nitrogenada, em cada ano, foi parcelada em três épocas após cada corte de avaliação da forrageira: a primeira aplicação foi realizada em dezembro, a segunda em janeiro e a terceira em fevereiro, todas com intervalo de 30 dias.

Durante os três anos do experimento, foram realizados três cortes por ano do capim-marandu, 30 dias após a aplicação do N. Em seguida, foram coletadas amostras de solo nas profundidades de 0-20 e 20-40 cm, para acompanhar a dinâmica do $\mathrm{N}$ e o efeito das doses e fontes de $\mathrm{N}$ nos atributos químicos do solo, nas duas profundidades.

A determinação do $\mathrm{pH}$ foi realizada em água; o $\mathrm{Al}$ trocável $\left(\mathrm{Al}^{3+}\right)$ foi extraído com $\mathrm{KCl} 1 \mathrm{~mol} \mathrm{~L}^{-1}$ e depois titulado com NaOH $0,025 \mathrm{~mol} \mathrm{~L}^{-1}$; a MOS foi determinada pela oxidação úmida com $\mathrm{Na}_{2} \mathrm{Cr}_{2} \mathrm{O}_{7}$ $2 \mathrm{~mol} \mathrm{~L}-1+\mathrm{H}_{2} \mathrm{SO}_{4} 5 \mathrm{~mol} \mathrm{~L}-1$; e o $\mathrm{N}$ total foi determinado pelo método de Kjeldahl, todos analisados por meio do método da Embrapa (1997). O N amoniacal $\left(\mathrm{N}-\mathrm{NH}_{4}{ }^{+}\right)$e o $\mathrm{N}$ nítrico $\left(\mathrm{N}-\mathrm{NO}_{3}{ }^{-}\right)$foram avaliados pelo método de destilação a vapor descrito por Tedesco et al. (1985).

Todas as variáveis receberam o tratamento estatístico pelo software SISVAR 4.6 (Ferreira, 2000). Foi realizada a análise de variância e, em função da significância para as variáveis, foram ajustadas equações de regressão. Utilizou-se o nível de significância de $5 \%$ em todos os testes estatísticos.

\section{RESULTADOS E DISCUSSÃO}

A interação doses de $\mathrm{N} x$ anos afetou o pH do solo, promovendo decréscimos lineares dos valores nas camadas de 0-20 e 20-40 cm com o aumento das doses de $\mathrm{N}$, em todos os anos de recuperação do capimmarandu (Figura 1a,b). Em relação à não-aplicação de $\mathrm{N}$, a maior dose (300 $\left.\mathrm{kg} \mathrm{ha}^{-1} \mathrm{ano}^{-1} \mathrm{de} \mathrm{N}\right)$ reduziu os valores de $\mathrm{pH}$ na camada de $0-20 \mathrm{~cm}$ em $0,6,1,2 \mathrm{e}$ 1,3 e na camada de $20-40 \mathrm{~cm}$, em $0,5,1,0$ e 1,0 unidades, para os anos de 2004, 2005 e 2006, respectivamente.

Observa-se na figura 1c,d que o sulfato de amônio promoveu maior acidificação do solo que a uréia em todas as doses aplicadas, em ambas as profundidades estudadas, concordando com Tisdale et al. (1993). Em 
relação à dose zero, a aplicação de $300 \mathrm{~kg} \mathrm{ha}^{-1}$ de N reduziu o $\mathrm{pH}$ do solo em 1,0 e 0,8 unidades para a fonte de sulfato de amônio e uréia, respectivamente, tanto para camada de 0-20 quanto para a de $20-40 \mathrm{~cm}$ de profundidade. Várias pequisas têm mostrado que os adubos nitrogenados acidificam o solo, como verificado por Primavesi et al. (2005) com aplicação de uréia e nitrato de amônio em capim-coastcross; por Campos (2004), com sulfato de amônio na cultura do milho em solo sob pastagem de capim-braquiária; e por Lange et al. (2006), com aplicação da uréia na cultura do milho.

A acidificação do solo pelo uso de adubos nitrogenados amoniacais, ou no caso da uréia, que gera amônio pela sua hidrólise, já era esperada, pois no processo de nitrificação há formação de dois prótons $\left(\mathrm{H}^{+}\right)$para cada íon de $\mathrm{NH}_{4}{ }^{+}$nitrificado (Campos, 2004; Moreira \& Siqueira, 2006).

De acordo com Malavolta (2006), adicionalmente à nitrificação, a absorção de cátions pelas raízes - neste trabalho especialmente o $\mathrm{NH}_{4}{ }^{+}$- também promove a acidificação do solo, devido à extrusão do $\mathrm{H}^{+}$celular para a solução do solo. Além disso, segundo o autor, o próprio tempo de cultivo promove acidificação do solo, em virtude da lixiviação e extração de bases pelas plantas, da exsudação de ácidos orgânicos pelas raízes, da hidrólise do $\mathrm{Al} \mathrm{e,} \mathrm{conseqüentemente,} \mathrm{aumento} \mathrm{dos}$ teores de $\mathrm{H}+\mathrm{Al}$ (Quadro 1). Esses fatos explicam a redução dos valores de $\mathrm{pH}$ com os anos de cultivos do capim-marandu, mesmo na ausência de aplicação do N (Figura 1a,b). A maior acidificação do solo no sulfato de amônio, em relação à uréia, deve-se a uma série de fatores, dentre eles a volatilização amônia da uréia aplicada em superfície e, com isso, as menores quantidades de $\mathrm{NH}_{4}{ }^{+}$nitrificado e de $\mathrm{H}^{+}$e $\mathrm{NO}_{3}{ }^{-}$ formados. Assim, o sulfato de amônio apresenta maior potencial de produzir $\mathrm{H}^{+}$; também o $\mathrm{SO}_{4}{ }^{2-}$ presente na sua estrutura e o $\mathrm{NO}_{3}$ formado promovem a lixiviação de bases, contribuindo para maior acidificação do solo.

A redução do $\mathrm{pH}$ observada na profundidade de 20-40 cm (Figura 1b,d) mostra que a acidificação provocada por adubos nitrogenados não se restringe apenas à camada superficial, mas afeta também a subsuperfície do solo, fato também observado por Lange et al. (2006). Certamente, a lixiviação de $\mathrm{NH}_{4}{ }^{+}$ pelo $\mathrm{SO}_{4}{ }^{2-}$ e $\mathrm{NO}_{3}$ - contribuiu para que o sulfato de amônio apresentasse maior acidificação em profundidade.
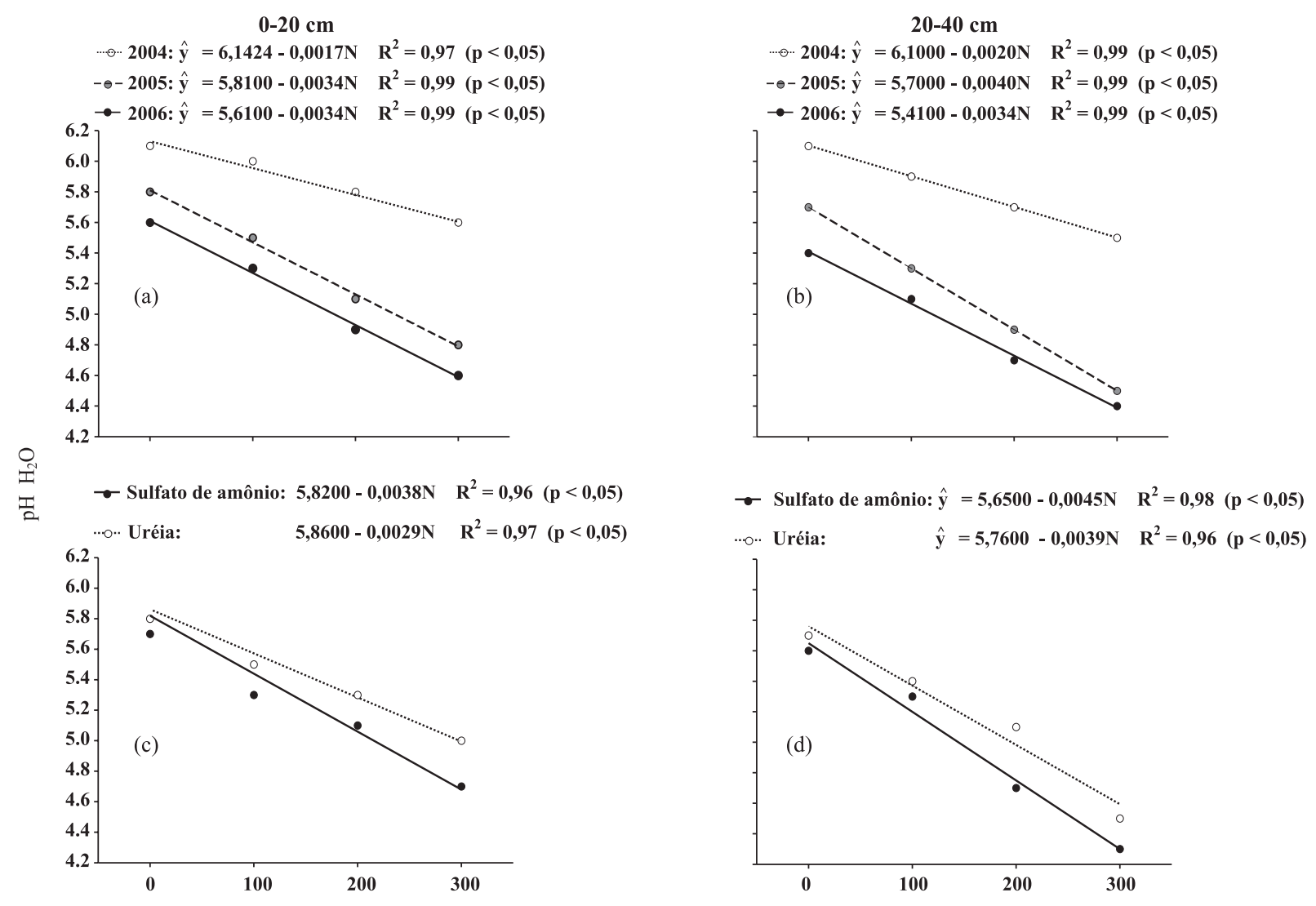

DOSES DE NITROGÊNIO, $\mathrm{kg} \mathrm{ha}^{-1} \mathrm{ano}^{-1}$

Figura 1. Efeito de doses e de fontes de nitrogênio sobre o pH do solo avaliado em diferentes épocas, nas camadas de 0-20 e 20-40 cm de profundidade. 
A maior concentração de $\mathrm{Al}^{3+}$ é uma conseqüência da acidificação do solo. Como as doses e fontes de $\mathrm{Ne}$ os anos de cultivo do capim-marandu promoveram a acidificação do solo (Figura 1), houve também aumento nos teores de $\mathrm{Al}^{3+}$ no solo, mostrando interação entre doses de $\mathrm{Nx}$ anos e doses $\mathrm{x}$ fontes de $\mathrm{N}$ para as camadas de 0-20 e 20-40 cm (Figura 2). Observa-se maior concentração de $\mathrm{Al}^{3+}$ no solo no ano de 2006, com a aplicação da maior dose de $\mathrm{N}\left(300 \mathrm{~kg} \mathrm{ha}^{-1} \mathrm{ano}^{-1}\right)$, na forma de sulfato de amônio. Esse aumento do teor de $\mathrm{Al}^{3+}$ como conseqüência da acidificação do solo causada pela aplicação de $\mathrm{N}$ na forma de sulfato de amônio também foi observado por Campos (2004). Segundo Carvalho et al. (1992), essa acidificação apresenta reflexos negativos na produtividade da pastagem, mesmo com o uso de espécies tolerantes à acidez, como as braquiárias.

Os teores de MOS foram influenciados pelas doses e fontes de $\mathrm{N}$ na camada de $0-20 \mathrm{~cm}$, apresentando ajuste linear com aumento das doses de $\mathrm{N}$, para ambas as fontes (Figura 3a).

Os teores encontrados de MOS nas maiores doses mostraram aumento de 48 \% para o sulfato de amônio e $42 \%$ para a uréia, em relação à não-aplicação de $\mathrm{N}$. $\mathrm{Na}$ maior dose de $\mathrm{N}$, os teores foram de 31,8 e $27,4 \mathrm{~g} \mathrm{dm}^{-3}$ para o sulfato de amônio e uréia, respectivamente; o sulfato de amônio foi superior em $16 \%$ em relação à uréia. Esse aumento nos teores de MOS pode ser justificado pela resposta da forrageira às doses de $\mathrm{N}$ em produção de massa seca do capimmarandu, também maior para o sulfato de amônio em relação à uréia, como demonstrado por Costa (2007).

Apesar de três anos de condução do experimento, os teores de MOS não foram influenciados pelos anos avaliados de recuperação da pastagem, nas duas profundidades. Em estudo da fertilização com $\mathrm{NeS}$ por dois anos na recuperação de pastagem de Brachiaria brizantha cv. Marandu, em Neossolo Quartzarênico, Oliveira et al. (2005) observaram queda no teor de MOS do solo em função do tempo. Batista (2006), trabalhando com doses de N e S na implantação do capim-marandu em substituição ao capim-braquiária em degradação num solo com baixa MO, verificou que o N aplicado em altas doses acelera a decomposição da MO, promovendo a redução do seu teor no solo.

As fontes de $\mathrm{N}$ e anos avaliados não influenciaram os teores de MOS na profundidade de $20-40 \mathrm{~cm}$; resposta significativa foi verificada apenas para as doses de N (Figura $3 b$ ). Os teores de MOS variaram de 13,5 a $19,8 \mathrm{~g} \mathrm{dm}^{-3}$, na ausência da adubação nitrogenada e maior dose aplicada, respectivamente.

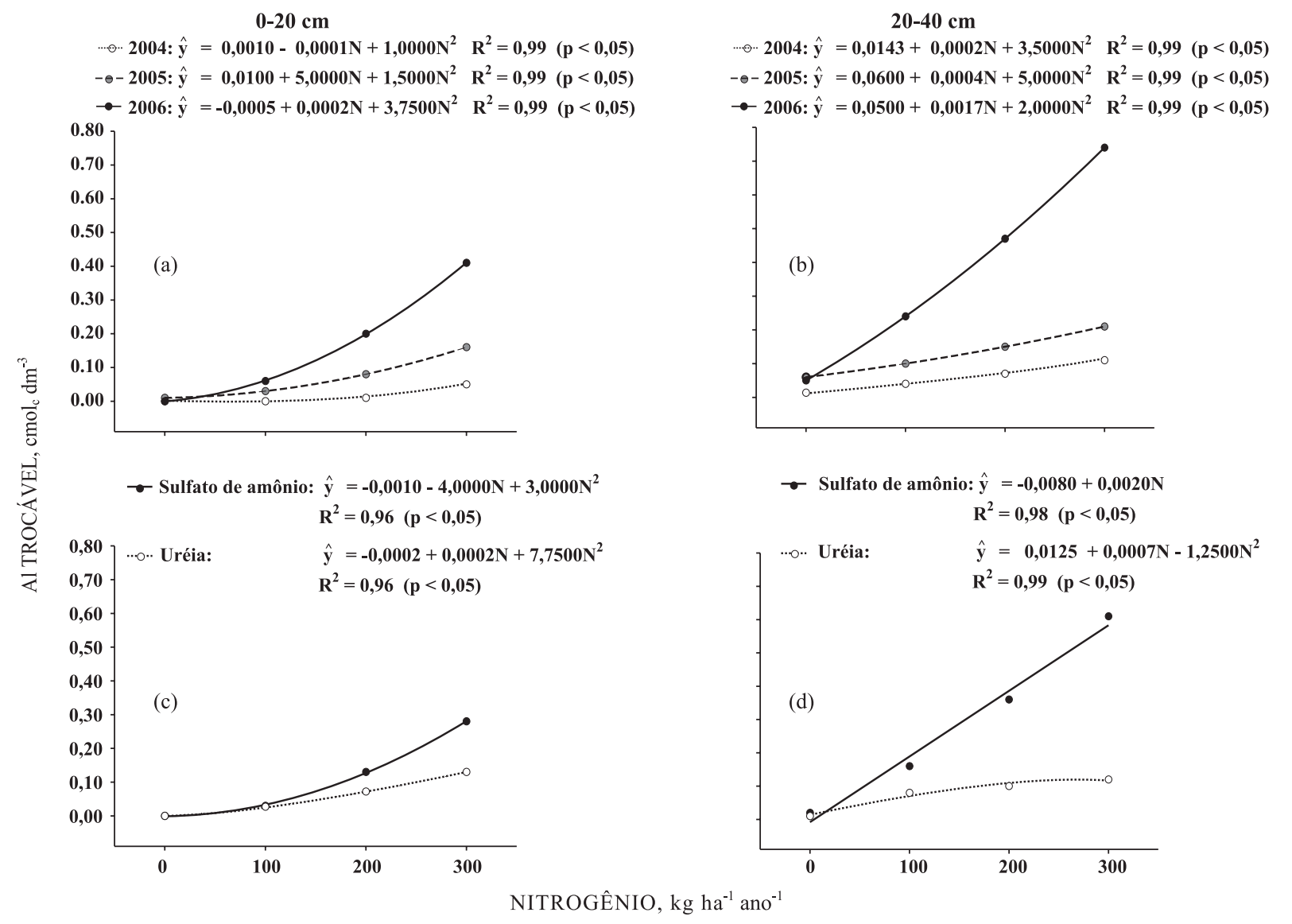

Figura 2. Efeito de doses e de fontes de nitrogênio sobre o teor de alumínio do solo avaliado em diferentes épocas, nas camadas de 0-20 e 20-40 cm de profundidade. 


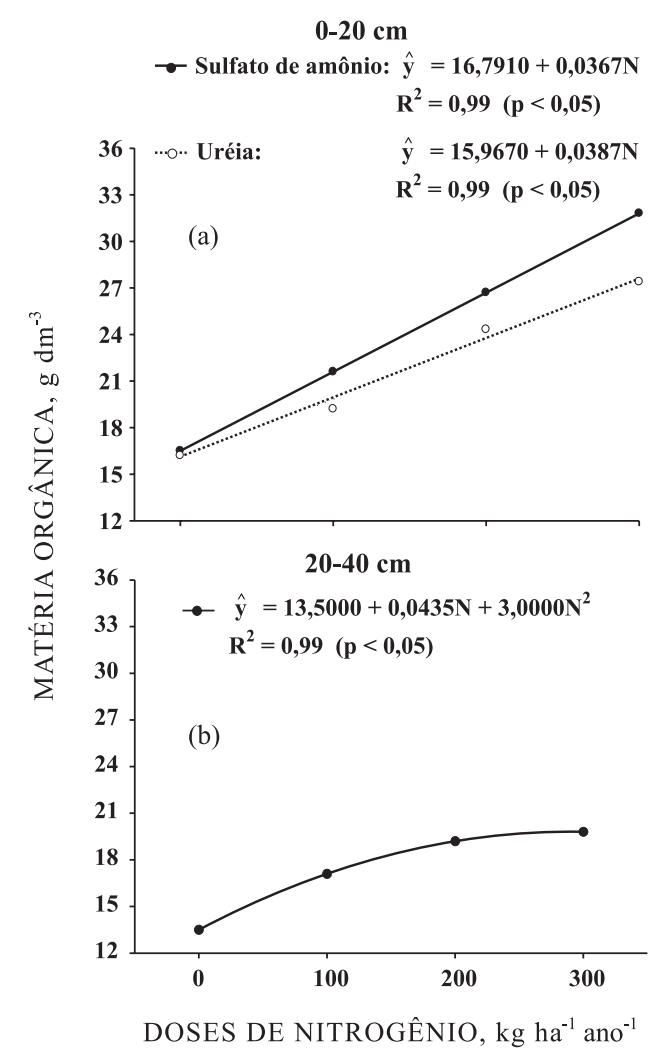

Figura 3. Teor de matéria orgânica do solo em função de doses e fontes de nitrogênio na camada de 0 $20 \mathrm{~cm}$ de profundidade (a) e em função de doses de nitrogênio na camada de $20-40 \mathrm{~cm}$ (b) de profundidade.

Os teores de $\mathrm{N}$ total não foram influenciados pelas fontes de $\mathrm{N}$ e pelos anos de avaliação nas duas profundidades, observando-se significância apenas para as doses de N (Figura 4). A MOS é a principal fonte de $\mathrm{N}$ do solo e, portanto, grande parte do $\mathrm{N}$ total do solo está na forma orgânica (Malavolta, 2006). Assim, como esperado, os teores de $\mathrm{N}$ total (Figura 4) apresentaram comportamento semelhante ao da MOS em função das doses de $\mathrm{N}$, nas duas profundidades. Observa-se aumento linear do $\mathrm{N}$ total com acréscimo nas doses de $\mathrm{N}$ na camada de 0-20 cm (Figura 4a) e quadrático na de 20-40 cm (Figura 4b), mostrando aumento na maior dose de N, de 27 e $24 \%$, em relação à não-aplicação do $\mathrm{N}$, respectivamente.

Em estudo com $\mathrm{N}$ e S em implantação do capimmarandu em solo com baixo teor de MO, Batista (2006) constatou respostas significativas no teor de $\mathrm{N}$ total apenas nas doses de N. Resultados semelhantes também foram obtidos por Bonfim-da-Silva (2005), que, em trabalho com doses de N e S no capim-marandu em degradação, verificou que, após os três cortes da planta forrageira, houve incremento no teor de $\mathrm{N}$ total no solo com o aumento das doses de N, independentemente da extração de nutrientes pelas plantas.
Os teores de $\mathrm{N}-\mathrm{NO}_{3}{ }^{-}$nas camadas de 0-20 e 20$40 \mathrm{~cm}$ não foram influenciados pela interação doses de $\mathrm{N} \mathrm{x}$ anos e doses $\mathrm{x}$ fontes de N. Entretanto, foi observado efeito significativo nesses teores apenas para as doses de $\mathrm{N}$, com ajuste quadrático para a camada de $0-20 \mathrm{~cm}$ e linear para a de 20-40 cm (Figura 5a,b). Comparando os teores de $\mathrm{N}-\mathrm{NO}_{3}{ }^{-}$sem adubos nitrogenados com as maiores doses empregadas, observa-se aumento de 68 e $67 \%$ para a camada de 0-20 e 20-40 cm, respectivamente. Esses resultados estão de acordo com os encontrados por Bonfim-daSilva (2005) e de Colozza et al. (2000).

Os teores de $\mathrm{N}^{-\mathrm{NO}_{3}}{ }_{3}^{-}$observados na camada de 20 $40 \mathrm{~cm}$ foram inferiores aos encontrados na de $0-20 \mathrm{~cm}$, mostrando que, apesar da aplicação de altas doses de $\mathrm{N}\left(300 \mathrm{~kg} \mathrm{ha}^{-1} \mathrm{ano}^{-1}\right)$, esse nutriente foi aproveitado pelas plantas, resultando em pequena lixiviação no perfil do solo, em razão de as braquiárias possuírem sistema radicular profundo. Nas duas profundidades estudadas, os teores de $\mathrm{N}-\mathrm{NO}_{3}$ - foram relativamente baixos no solo. Isso pode ser explicado pelo fato de as gramíneas tropicais serem excelentes extratoras de $\mathrm{N}$ do solo (Primavesi et al., 2001; Cantarella et al., 2003).

Varias pesquisas têm mostrado que as perdas de $\mathrm{N}$ por lixiviação não parecem ser motivo de preocupação em pastagens tropicais bem manejadas

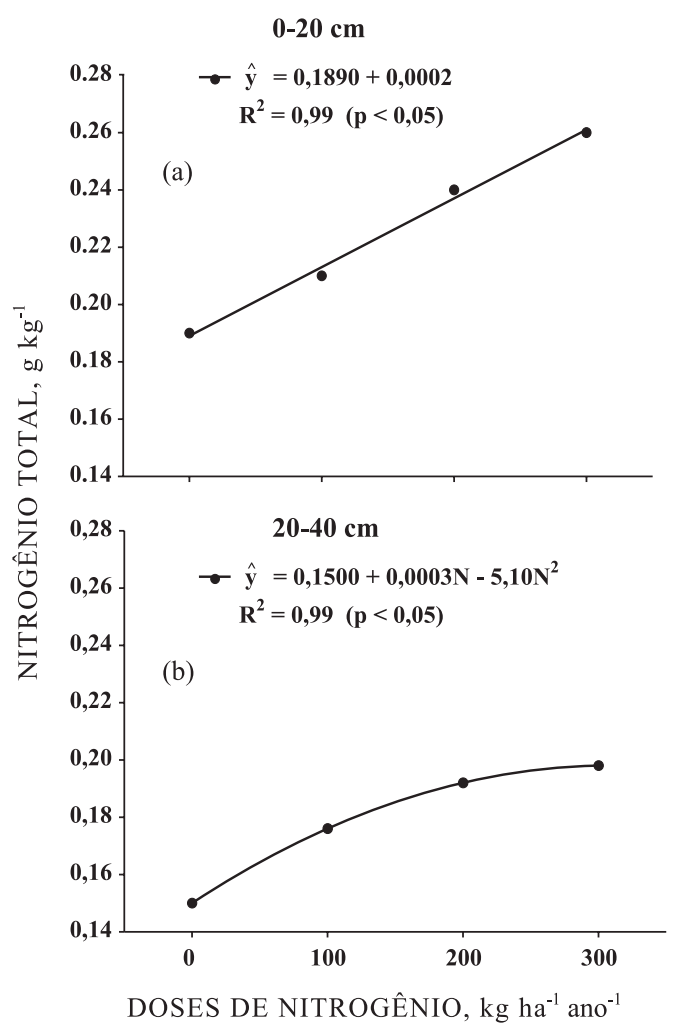

Figura 4. Teor de nitrogênio total do solo nas camadas de 0-20 (a) e 20-40 cm (b) de profundidade, em função de doses de nitrogênio. 
(Martha Júnior, 1999; Prasertsak et al., 2001). Esses estudos indicaram que menos de $5 \%$ do $\mathrm{N}$ aplicado é lixiviado para camadas de solo superiores a $30 \mathrm{~cm}$ de profundidade. Esses autores ressaltam ainda que a expectativa de lixiviação de $\mathrm{N}_{-} \mathrm{NO}_{3}{ }^{-}$é pequena em pastagens tropicais, uma vez que o $\mathrm{N}$ "perdido" da camada superficial do solo (20 a $30 \mathrm{~cm})$ pode ser absorvido pela planta forrageira em maiores profundidades. Além do mais, a maioria dos solos utilizados com pastagens (Latossolos e Argissolos) no Brasil são profundos e vegetados por plantas forrageiras de elevada capacidade de extração de nutrientes, diminuindo ainda mais a possibilidade de lixiviação de $\mathrm{N}_{-} \mathrm{NO}_{3}{ }^{-}$. Para Martha Júnior \& Vilela (2002), esses fatos sinalizam que os problemas de lixiviação de $\mathrm{N}$ do fertilizante em solos vegetados por gramíneas tropicais podem ser ainda menores do que o esperado (3 a $5 \%$ do $\mathrm{N}$ aplicado). Em estudo de lixiviação de nitrato em pastagem de capim-coastcross adubada com doses de $\mathrm{N}$ de 125, 250, 500 e $1.000 \mathrm{~kg} \mathrm{ha}^{-1} \mathrm{ano}^{-1}$, na fonte de uréia e nitrato de amônio, Primavesi et al. (2006) verificaram que na dose de $\mathrm{N}$ de até $500 \mathrm{~kg} \mathrm{ha}^{-1}$ não houve perdas significativas de nitrato para o lençol freático.

Em ambas as profundidades, os teores de $\mathrm{N}-\mathrm{NH}_{4}{ }^{+}$ do solo não foram influenciados quando comparados os três anos de avaliação da forrageira. Contudo, houve efeito significativo das doses e fontes de $\mathrm{N}$ para a camada de $0-20 \mathrm{~cm}$, com ajuste quadrático para o sulfato de amônio e linear para a uréia (Figura 5c). As médias ajustadas ficaram entre $11,84 \mathrm{e}$ $56,34 \mathrm{mg} \mathrm{kg}^{-1}$ para sulfato de amônio e entre 10,69 e $48,09 \mathrm{mg} \mathrm{kg}^{-1}$ para a uréia, com incremento de $78 \mathrm{e}$ 77 \%, em relação à não-aplicação do adubo nitrogenado, respectivamente. Para a profundidade de $20-40 \mathrm{~cm}$, as doses de $\mathrm{N}$ influenciaram linearmente os teores de $\mathrm{N}-\mathrm{NH}_{4}{ }^{+}$no solo, atingindo valores de $31,92 \mathrm{mg} \mathrm{kg}^{-1}$ na maior dose estudada, com incremento de $59 \%$ em relação à não-aplicação de $\mathrm{N}$ (Figura $5 \mathrm{~d}$ ). Em pesquisas realizadas com doses de $\mathrm{N}$ e $\mathrm{S}$ na recuperação de pastagens do capim-marandu, Bonfimda-Silva (2005) e Batista (2006) verificaram aumentos lineares nos teores de $\mathrm{N}-\mathrm{NH}_{4}{ }^{+}$no solo, com acréscimos das doses de $\mathrm{N}$ aplicadas.

Embora não comparados estatisticamente, observase que, nos tratamentos em que se aplicou $\mathrm{N}$ (doses de 100,200 e $300 \mathrm{~kg} \mathrm{ha}^{-1} \mathrm{ano}^{-1}$ ), os teores de N-NH${ }_{4}^{+}$ no solo foram sempre maiores que o de $\mathrm{N}_{-} \mathrm{NO}_{3}{ }^{-}$ (Figura 5). Segundo Moreira \& Siqueira (2006), o processo de nitrificação é mediado pelas bactérias dos gêneros Nitrosomonas e Nitrobacter, sendo essas muito sensíveis a valores de $\mathrm{pH}$ menores que 6,0 e nulas em pH menor que 4,5. Como a aplicação de $\mathrm{N}$ por ambas as fontes reduziu o $\mathrm{pH}$ do solo (Figura 1), esse fato explica o maior teor de $\mathrm{N}-\mathrm{NH}_{4}{ }^{+}$em relação ao $\mathrm{N}_{-} \mathrm{NO}_{3}{ }^{-}$, principalmente na profundidade de $0-20 \mathrm{~cm}$. Silva \& Vale (2000), estudando o efeito da calagem e de fontes e doses de $\mathrm{N}$ na disponibilidade de nitrato
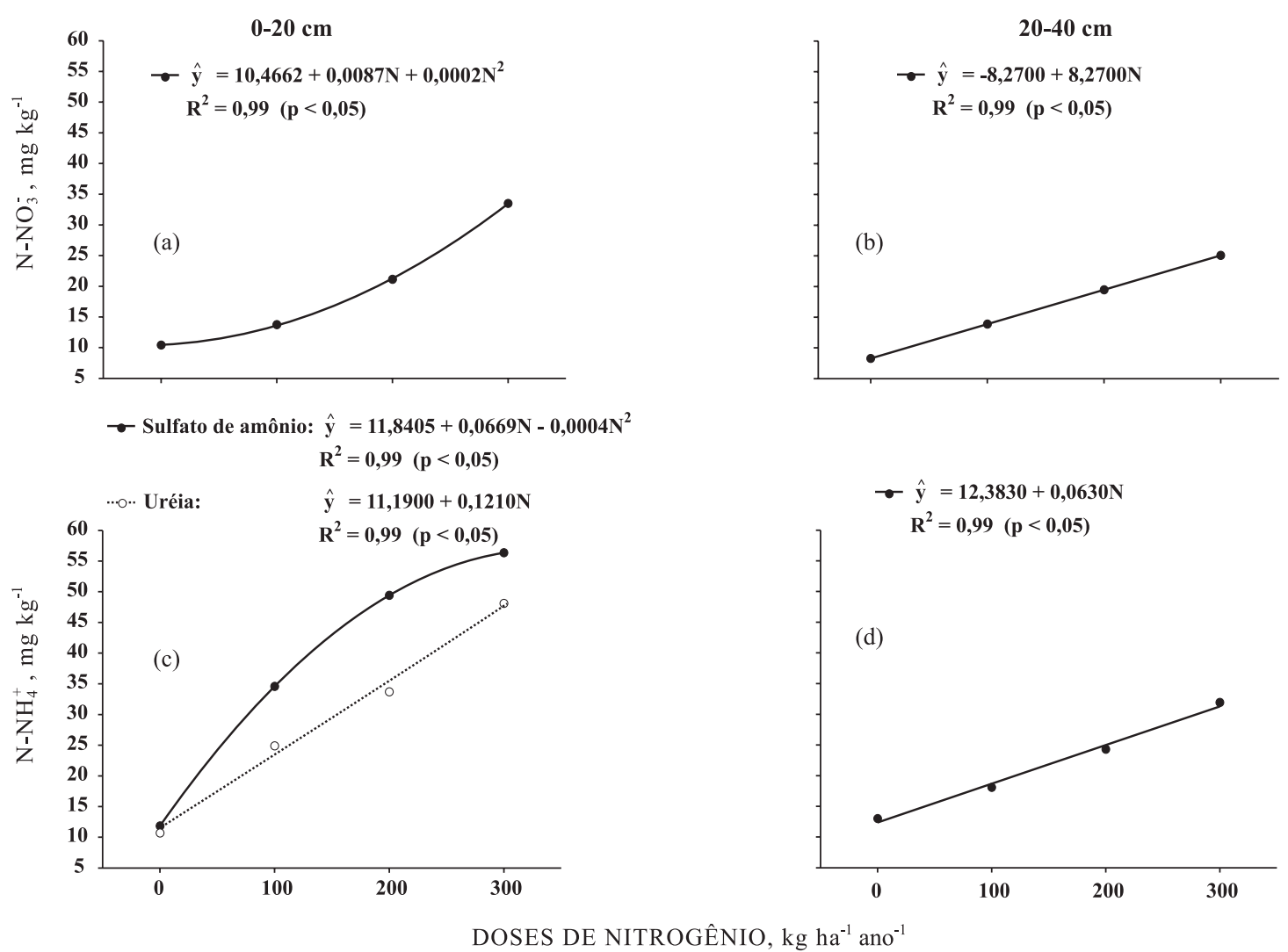

Figura 5. Teores de nitrato (a e b) e de amônio (c e d) do solo nas camadas de 0-20 e 20-40 cm de profundidade em função de doses e, ou, de fontes de nitrogênio. 
em solos brasileiros, mostraram, para a maioria dos solos, que o abaixamento do $\mathrm{pH}$ promoveu drástica redução da nitrificação e que, em $\mathrm{pH}$ de 4,9 a 5,2, muito pouco $\mathrm{N}_{-} \mathrm{NO}_{3}{ }^{-}$foi formado. Campos (2004), trabalhando com sulfato de amônio na cultura do milho em solo sob pastagem de capim-braquiária, constatou maior predominância da forma amoniacal sobre a nítrica.

\section{CONCLUSÕES}

1. Após três anos de aplicação contínua nas maiores doses de $\mathrm{N}$, o $\mathrm{pH}$ do solo diminuiu de 5,6 para 4,6 e o teor de $\mathrm{Al}^{3+}$ aumentou de 0,05 para $0,41 \mathrm{cmol}_{\mathrm{c}} \mathrm{dm}^{-3}$; o sulfato de amônio causou maior acidificação do solo em relação à uréia.

2. A aplicação de doses elevadas de $\mathrm{N}$ aumentou os teores de $\mathrm{Al}^{3+}, \mathrm{MO}, \mathrm{N}$ total, $\mathrm{N}-\mathrm{NO}_{3}{ }^{-}$e N-NH${ }_{4}{ }^{+}$no solo; os teores de $\mathrm{N}-\mathrm{NH}_{4}{ }^{+}$foram mais elevados que os de N$\mathrm{NO}_{3}{ }^{-}$.

\section{LITERATURA CITADA}

AITA, C. \& GIACOMINI, S.J. Matéria orgânica do solo, nitrogênio e enxofre nos diversos sistemas de exploração agrícola. In: SIMPÓSIO SOBRE NITROGÊNIO E ENXOFRE NA AGRICULTURA BRASILEIRA, Piracicaba, 2007. Anais. Piracicaba, IPNI Brasil, 2007. 722p.

BATISTA, K. Nitrogênio e enxofre na implantação do capimmarandu em substituição ao capim-braquiária em degradação num solo com baixa matéria orgânica. Piracicaba, Escola Superior de Agricultura Luiz de Queiroz, 2006. 125p. (Tese de Doutorado)

BONFIM-DA-SILVA, E.M. Nitrogênio e enxofre na recuperação de capim-braquiária em degradação em Neossolo Quartzarênico com expressiva matéria orgânica. Piracicaba, Escola Superior de Agricultura Luiz de Queiroz, 2005. 123p. (Tese de Doutorado)

CAMPOS, A.X. Fertilização com sulfato de amônio na cultura do milho em um solo do Cerrado de Brasília sob pastagem de Brachiaria decumbens. Piracicaba, Escola Superior de Agricultura Luiz de Queiroz, 2004. 119p. (Tese de Doutorado)

CANTARELLA, H.; MATTOS JÚNIOR, D.; QUAGGIO, J.A. \& RIGOLIN, A.T. Fruit yield of Valencia sweet orange fertilized with different $\mathrm{N}$ sources and the loss of applied N. Nutr. Cycling Agroec., 67:215-223, 2003.

CARVAlho, M.M.; MARTINS, C.E.; SIQUEIRA, C. \& SARAIVA, O.F. Crescimento de uma espécie de braquiária, na presença de calagem em cobertura e doses de nitrogênio. R. Bras. Ci. Solo, 16:69-74, 1992.

COLOZZA, M.T.; KIEHL, J.C.; WERNER, J.C. \& SCHAMMASS, E.A. Repostas de Panicum maximum cv. Aruana a doses de nitrogênio. B. Ind. Animal, 57:21-32, 2000.

COSTA, K.A.P. Doses e fontes de nitrogênio na recuperação de pastagem de capim-marandu em solo de Cerrado. Lavras, Universidade Federal de Lavras, 2007. 95p. (Tese de Doutorado)
EMPRESA BRASILEIRA DE PESQUISA AGROPECUÁRIA EMBRAPA. Centro Nacional de Pesquisa de Solos. Ministério da Agricultura e do Abastecimento. Manual de Métodos de Análise de Solo. 2.ed. rever. e atual. Rio de Janeiro: Embrapa CNPS, 1997. 212p.

EMPRESA BRASILEIRA DE PESQUISA AGROPECUÁRIA EMBRAPA. Centro Nacional de Pesquisa de Solos. Sistema brasileiro de classificação de solos. 2.ed. Rio de Janeiro, 2006. 306p.

FERREIRA, D.F. Análises estatísticas por meio do SISVAR para Windows versão 4.0. In: REUNIÃO ANUAL DA REGIÃO BRASILEIRA DA SOCIEDADE INTERNACIONAL DE BIOMETRIA. São Carlos, 2000. Anais. São Carlos, Universidade Federal de São Carlos, 2000. p.255-258.

LANGE, A.; CARVALHO. J.L.N.; DAMIN, V.; CRUZ, J.C. \& MARQUES, J.J. Alterações em atributos do solo decorrentes da aplicação de nitrogênio e palha em sistema semeadura direta na cultura do milho. Ci. Rural, 36:460467, 2006.

MALAVOLTA, E. Manual de nutrição de plantas. São Paulo, Ceres, 2006. 638p.

MARSCHNER, H. Mineral nutrition of higher plants. London, Academic Press, 1997. 889p.

MARTHA JÚNIOR, G.B.; CORSI, M.; TRIVELIN, P.C.O.; VILELA, L.; PINTO, T.L.F.; TEIXEIRA, G.M.; MANZONI, C.S. \& BARIONI, L.G. Perdas de amônia por volatilização em pastagem de capim-tanzânia adubada com uréia no verão. R. Bras. Zootecnia, 33:2240-2247, 2004.

MARTHA JÚNIOR, G.B. Balanço de ${ }^{15} \mathrm{~N}$ e perdas de amônia por volatilização em pastagem de capim-elefante. Piracicaba, Escola Superior de Agricultura "Luiz de Queiroz", 1999. 75p. (Tese de Mestrado)

MARTHA JÚNIOR, G.B. \& VILELA, L. Pastagens no Cerrado: baixa produtividade pelo uso limitado de fertilizantes em pastagens. Planaltina, Embrapa Cerrados, 2002. 32p. (Documentos, 50)

MOREIRA, F.M.S. \& SIQUEIRA, J.O. Microbiologia e bioquímica do solo. 2.ed. Lavras, Universidade Federal de Lavras, 2006. 729p.

OLIVEIRA, P.P.A.; TRIVALIN, P.C.O.; OLIVEIRA, W.S. \& CORSI, M. Fertilização com nitrogênio e enxofre na recuperação de pastagem de Brachiaria brizantha cv. Marandu em Neossolo quartzarênico. R. Bras. Zootecnia., 34:1121-1129, 2005.

PAIVA, P.J.R. Parâmetros de fertilidade de um solo do Paraná sob diferentes sistemas de manejo. Piracicaba, Escola Superior de Agricultura Luiz de Queiroz, 1990. 55p. (Tese de Mestrado)

PRASERTSAK, P.; FRENEY, J.R. \& DENMEAD, O.T. Significance of gaseous nitrogen loss from a tropical dairy pasture fertilized with urea. Aust. J. Exp. Agric., 41:625632, 2001.

PRIMAVESI, A.C.; PRIMAVESI, O.; CORREAA, L.A.; CANTARELLA, H. \& SILVA, A.G. Absorção de cátions e ânions pelo capim-Coastcross adubado com uréia e nitrato de amônio. Pesq. Agropec. Bras., 40:247-253, 2005. 
PRIMAVESI, A.C.; PRIMAVESI, O.; CORREA, L.A.; CANTARELlA, H.; SILVA, A.G.; FREITAS, A.R. \& VIVALDI, L.J. Adubação nitrogenada em capim. coastcross: efeitos na extração de nutrientes e recuperação aparente do nitrogênio. R. Bras. Zootecnia, 33:68-78, 2004.

PRIMAVESI, A.C.; PRIMAVESI, O.; CORRÊA, L.A.; SILVA, A.G. \& CANTARELLA, H. Lixiviação de nitrato em pastagens de coastcross adubada com nitrogênio. R. Bras. Zootecnia, 35:683-690, 2006.

PRIMAVESI, O.; CORRÊA, L.A. \& PRIMAVESI, A.C. Adubação com uréia em pastagem de Cynodon dactylon cv. Coastcross sob manejo rotacionado: eficiência e perdas. São Carlos, Embrapa Pecuária Sudeste, 2001. 42p. (Circular Técnica, 30)

SILVA, C.A. \& VALE, F.R. Disponibilidade de nitrato em solos brasileiros sob efeito da calagem e de fontes e doses de nitrogênio. Pesq. Agropec. Bras., 35:2461-2471, 2000.
SILVA, F.C. Manual de análises químicas de solos, plantas e fertilizantes. Brasília, Embrapa, Informação Tecnológica, 1999. 370p.

SOUSA, D.M.G. \& LOBATO, E. Cerrado: correção do solo e adubação. 2.ed. Brasília, Embrapa Informação Tecnológica, 2004. 416p.

SOUSA, D.M.G.; VILELA, L. \& LOBATO, E. Uso do gesso, calcário e adubos para pastagens no Cerrado. Planaltina, Embrapa Cerrados, 2001. 22p. (Embrapa Cerrados. Circular Técnica, 12)

TEDESCO, M.J.; VOLKWEISS, S.J. \& BOHNEN, H. Análises de solo, plantas e outros materiais. Porto Alegre, Universidade Federal do Rio Grande do Sul, 1985. 95p. (Boletim Técnico, 5)

TISDALE, S.M.; NELSON, W.L.; BEATON, J.D. \& HAVLIN, J.L. Soil fertilility and fertilizers. 5.ed. New York, Macmillan Publishing Company, 1993. 634p. 